\title{
USE OF SHAKEDOWN MAPS TO ASSESS PLASTIC FLOW IN RAILWAY CURVES
}

\author{
S.J. Hawksbee ${ }^{1}$ ", G. J. Tucker ${ }^{1}$, M. Burstow ${ }^{2}$ \\ ${ }^{1}$ Institute of Railway Research, University of Huddersfield, Huddersfield, HD1 3DH, UK \\ ${ }^{2}$ Network Rail Infrastructure Ltd, The Quadrant:MK, Elder Gate, Milton Keynes, MK9 1EN \\ *E-mail: s.j.hawksbee@hud.ac.uk
}

\begin{abstract}
Plastic deformation of rails can occur on tight curves, which can significantly reduce rail life. This paper investigated the phenomena of gross plastic deformation, or plastic flow, using multibody vehicle-track interaction and simplified finite element analysis. The focus is on understanding the contact conditions on the low rail of curves and how these differ from those in shakedown maps. To this end, two trial sites are simulated using multibody vehicle-track software. The contact conditions are then compared against several criteria assumed in the derivation of the shakedown maps. A further assumption implicit in the shakedown maps is also investigated by a non-linear finite element analysis. In this case, a more realistic Chaboche material model is used as opposed to the simple linear elastic perfectly plastic model in shakedown theory. The results of the finite element analysis are combined with a bespoke indicator of plastic flow to assess the influence of distance to shakedown limits on likely plastic flow. Finally, a simple interpolation scheme is used to map the finite element results back to the trial sites. The interpolated results for the sites are used to evaluate the influence of running speed and different levels of wheel profile wear. Results suggest that the bespoke indicator defined in this work can be used as an effective measure of plastic flow; this measure is then used to quantify the influence of cant excess on rates of plastic flow.
\end{abstract}

Keywords: rail life, railway track, plastic deformation, shakedown, FEA

\section{Introduction}

Gross plastic deformation, also known as plastic flow, is often evident on both the high (outer) and low (inner) rails of tight radius curves, particularly on freight routes. Plastic flow in low rails tends to displace material from the rail head toward the field side, see Figure 1. Whereas, plastic deformation in the high rail displaces material from the gauge face downward and outward to cause 'lipping'. The detailed mechanism of plastic flow is not completely understood. However, high rates of plastic flow can significantly reduce rail life.
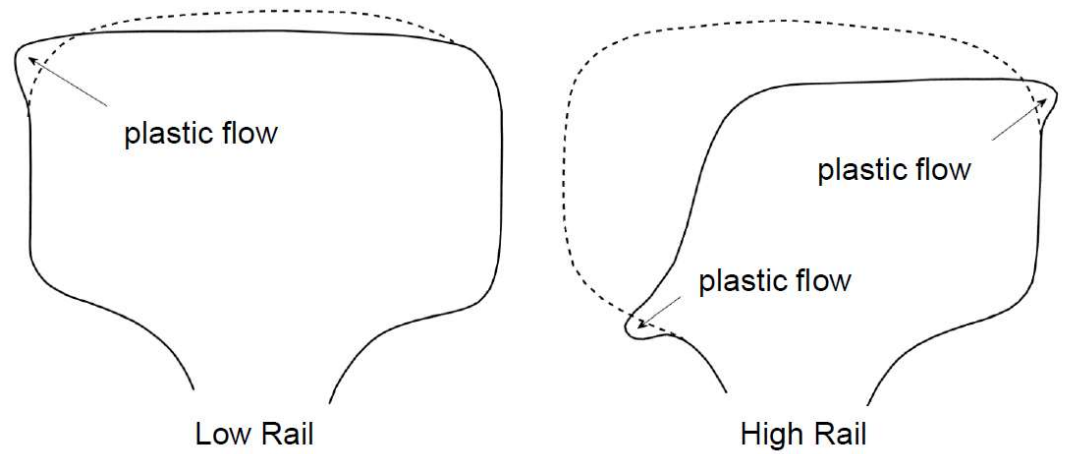

Figure 1 Plastic deformation of rails in a curve [1]

Contact stresses at the wheel rail interface frequently exceed the elastic limit of the rail steel; however, severe plastic flow is not experienced everywhere across the network. Severe plastic flow is prevented by the build-up of 'protective' residual stresses over a finite number load cycles to allow an ongoing 'elastic response'. Shakedown limits can therefore be established below which the material eventually returns to an elastic response and above which ratcheting failures are likely. It is assumed that only limited plastic deformation will occur below the shakedown limit, but gross deformations occur during progressive ratcheting failure when the shakedown limit is exceeded.

Therefore, the shakedown theorems [2], [3] have been extensively used to design against ratcheting failures. For example, Ponter's [4] shakedown maps are commonly used to design against ratcheting failures in rails. However, Ponter's shakedown maps are only valid for: (a) circular Hertzian contacts; (b) 'traction loads' (i.e. tangential contact forces) in the direction of travel. These simplifications may be valid for straight track with new wheels and rails; however, in practice contact shape and direction of tangential contact forces varies due to curvature and the worn shape of wheels and rails. A further study by Ponter et al [5] demonstrated that both these factors may significantly influence shakedown limits. This is demonstrated via some selected shakedown maps in Figure 2. Note that both Ponter [4] and Ponter et al [5] provide differing shakedown maps for circular contacts with longitudinal traction. Due to the upper bound nature of both 
shakedown maps, an improved shakedown map can be obtained, using the lowest of the two for a given traction coefficient. This combined shakedown map will be used in the remainder of this paper for circular contacts and longitudinal traction.

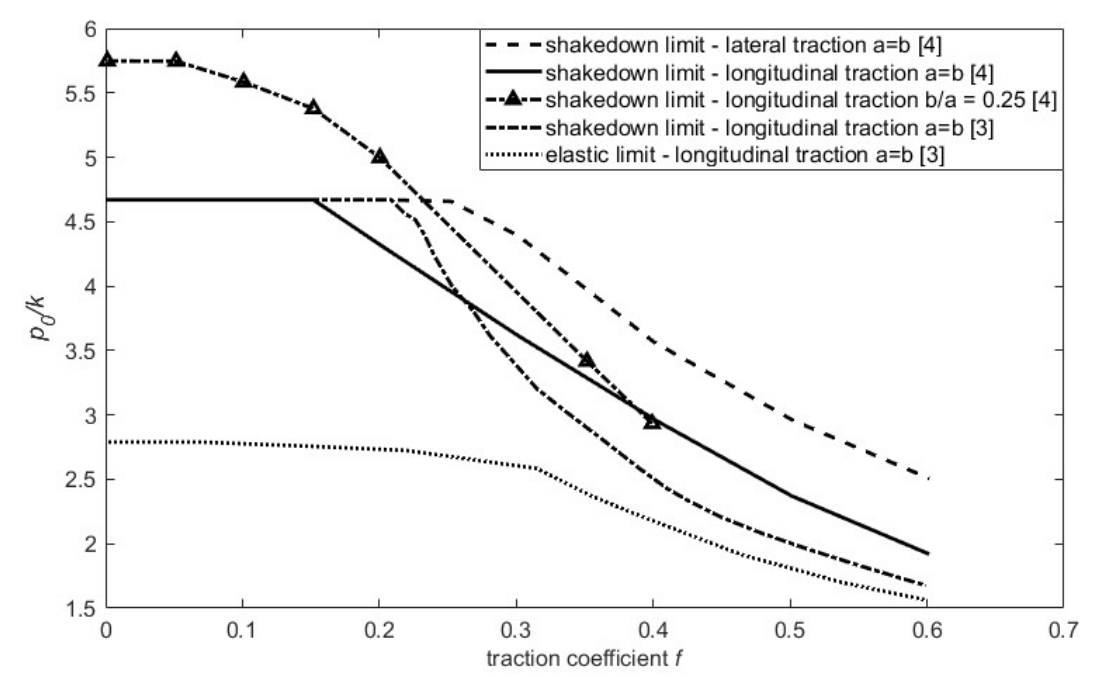

Figure 2 Selected shakedown maps [a is longitudinal semi-axis, $\boldsymbol{b}$ is lateral semi-axis, $p_{0}$ is peak normal stress and $k$ is the shear strength]

Both of these studies [3], [4] assume Hertzian contact conditions and approximate the contacting bodies as semi-infinite half-spaces. However, in practice shakedown limits reduce as the contact patch nears the rail edge [6]. In such cases, the half-space assumption is no longer valid. The shakedown maps also assume full-slippage between the wheel and rail such that the tangential tractions are elliptically distributed within the contact area. Johnson [7] has shown that partial slip conditions will reduce the shakedown limits. However, Johnson only considered line contacts. In practice, Ponter's [4] original shakedown map is often used indiscriminately without considering the limitations described.

The shakedown limits discussed so far consider contacts in isolation; however, shakedown limits may be reduced by the passage of contacts with different traction coefficients [8]. Alternatively, non-linear finite elements methods including contacting bodies have been used to study plastic flow [9]-[11]. However, these methods are typically complex and computationally intensive. Results are highly sensitive to the chosen material model and loading. Results are therefore not easily transferable to alternative materials or loadings.

Wheel-rail contacts in curves are highly elliptical with resultant tangential contact forces at a significant angle to the direction of travel. In some cases, the contacts may also approach the edge of the rail. These combinations are not covered by the shakedown maps in [4] and [5]. Furthermore, rail steels don't fit the idealized elastic-perfectly plastic material model assumed by classic shakedown analysis. Extensions [12], [13] to classic shakedown theory allow consideration of a wider range of materials including linear and non-linear hardening. Application of these shakedown theory extensions to contact mechanics are currently limited. However, Johnson [14] considered unlimited kinematic hardening for a small range of contact conditions, but excluding those most relevant to lateral plastic flow in rails. Consequently, normalizing the contact conditions for assessment against shakedown maps requires a judgement as to the 'best' normalizing shear strength $k$. Further, the rate accumulation of plastic flow, particularly lateral plastic flow, at different distances from the shakedown maps under consideration are not well understood. Simple analytical methods have been used estimate rates of longitudinal plastic flow [15], [16], however, rates of lateral plastic flow accumulation have received little attention.

At the present time, therefore, simple models or tools capable of predicting the location and severity of plastic flow do not exist. Consequently, it is difficult to analytically assess potential measures aimed at reducing plastic flow, and infrastructure managers are unable to determine the optimum solutions to improve rail life. At the moment the option that is commonly used appears to be re-railing with higher grade steel, but the benefit of this (in terms of extended rail life) cannot be determined beforehand.

In the current study, two tight radius curves with a known history of low rail plastic flow are considered. Multibody vehicle-track simulations have been used to calculate the wheel-rail contact conditions for each site. These are used to understand how real contact conditions deviate from the contact conditions assumed by Ponter [4]. A bespoke indicator of plastic flow is then calculated based on these contact conditions. The bespoke indicator is developed by applying a range of Hertzian contact conditions to a non-linear finite element simulation using a more realistic material model. 


\section{Site descriptions}

Two sites with a history of field side plastic flow have been select for investigation. Both site have standard grade R260 steel and when new, a CEN56E1 (BS113A) rail profile. For both sites, measured rail profiles have been collected using a MiniProf device [17].

\subsection{Site A}

Site $A$ is a $280 \mathrm{~m}$ radius curve with an installed cant of $60 \mathrm{~mm}$ and $6 \mathrm{~mm}$ gauge widening (i.e. a gauge of $1441 \mathrm{~mm}$ ). The site was monitored over time to see how the rail profile shape changed as a result of passing traffic. The rail was initially ground to restore it to a CEN56E1 (BS113A) profile shape, then subsequent monitoring visits were undertaken at 4 weeks, 4 months and 9 months after this. During the monitoring visits, measurements of the rail profiles were collected using a MiniProf device. Figure 3 shows a close up view of the evolution of plastic flow on the field side of the low (inner) rail, which developed in the relatively short time of 8 months.

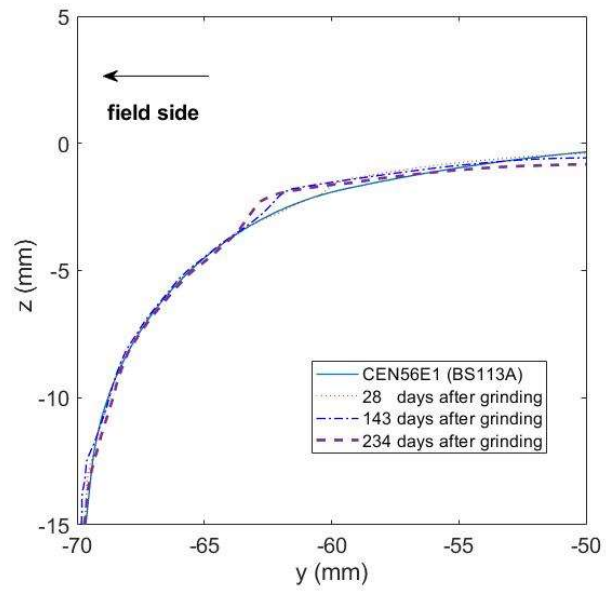

Figure 3 Site A - close up plastic flow in measured profiles

Table 1 summarizes the vehicle traffic though Site A at the time of the trial, given in wheelset passes per year.

Table 1 Site A - Vehicle traffic

\begin{tabular}{|c|c|c|c|}
\hline Vehicle type & $\begin{array}{c}\text { Annual Wheelset Passes } \\
\text { (passes/yr) }\end{array}$ & $\begin{array}{c}\text { Annual } \\
\text { Traffic } \\
\text { Tonnage } \\
\text { (Million gross } \\
\text { tonnes/yr) }\end{array}$ & Wheel Profile \\
\hline 2 axle passenger vehicle & 120,000 & 1.9 & P8 \\
\hline 4 axle passenger vehicle & 165,000 & 1.5 & P8 \\
\hline Laden freight wagon A & 200,000 & 5.0 & P5 \\
\hline
\end{tabular}

\subsection{Site B}

Site $\mathrm{B}$ is a $240 \mathrm{~m}$ radius curve with an installed cant of $65 \mathrm{~mm}$ and $2 \mathrm{~mm}$ of gauge widening (i.e. $1437 \mathrm{~mm}$ gauge). For this site, only a single measured rail profile was available. The site links two mainlines and carries only laden freight traffic, see Table 2. Note that laden freight wagon $\mathrm{A}$ is the same freight wagon as that present at site $\mathrm{A}$.

Table 2 Site B - Vehicle traffic

\begin{tabular}{|l|l|l|l|}
\hline Vehicle & $\begin{array}{l}\text { Annual } \\
\text { Wheelset } \\
\text { Passes } \\
\text { (passes/year) }\end{array}$ & $\begin{array}{c}\text { Annual } \\
\text { Traffic } \\
\text { Tonnage } \\
\text { (Million gross } \\
\text { tonnes/yr) }\end{array}$ & $\begin{array}{l}\text { Wheel } \\
\text { Profile }\end{array}$ \\
\hline $\begin{array}{l}\text { Laden freight } \\
\text { wagon A }\end{array}$ & 136,000 & 3.4 & P5 \\
\hline $\begin{array}{l}\text { Laden freight } \\
\text { wagon B }\end{array}$ & 140,000 & 3.5 & P8 \\
\hline
\end{tabular}

\section{Vehicle-track interaction simulations}


A multibody vehicle dynamics software, Vampire ${ }^{\circledR}[18]$, was used to simulate vehicles on both sites; the lighter passenger vehicles on site A were excluded from the study. Laden freight wagon A has an axle load of $250 \mathrm{kN}$, Swing Motion bogies (SMB) and P5 wheel profiles [19]. Laden freight wagon B also has an axle load of $250 \mathrm{kN}$, TF25 bogies and P8 wheel profiles [19]. A range of vehicle speeds were simulated for both sites giving cant excesses up to $57 \mathrm{~mm}$ and cant deficiencies up to $110 \mathrm{~mm}$. Wheel-rail friction $(\mu)$ of 0.3 has been assumed throughout. The Vampire simulations assume a Hertzian distribution for the normal force, and uses a creep-creep force look up table based on Kalker theory[20] for the tangential force calculations.

To take into account the varying worn wheel shapes, three different wheel conditions have been considered: new, moderately worn and heavily worn. Typically, the centre of the tread becomes flatter as wheels on heavily laden freight wagons wear; this means it is possible for the wheel to contact the rail closer to the field side of a low rail in a curve, especially if that rail is also heavily worn. Results in the following section are only presented for the leading two wheelsets of the wagons.

\subsection{Contact position}

To assess the validity of the half-space assumption in Ponter et al. [4], [5] work, the range of contact positions found for both sites are presented in Figure 4 and Figure 5. Note that Figure 4 summarises the contact conditions for the three measured rail profiles. For each wheel-rail combination, a running band is obtained by superimposing the contacts for leading and trailing wheelsets and for each running speed simulated. These show as expected that as both wheel and rail wear the running band shifts further toward the field side. The majority of the contacts are toward the centre of the rail; for these, the half-space assumption in Ponter et al [4], [5] is likely to be valid. However, Figure 5 shows that the heavily worn P8 wheel profile contacts the rail close to the field side edge. At this point on the rail head, a substantial volume of rail steel has displaced from elsewhere to create a 'bulge' above the original profile. The load bearing capacity of this displaced material may be severely compromised due to potential cracks or voids below the measured rail profile. In which case, the half-space assumption may no longer be valid. Investigation of this aspect is beyond the scope of the current study.

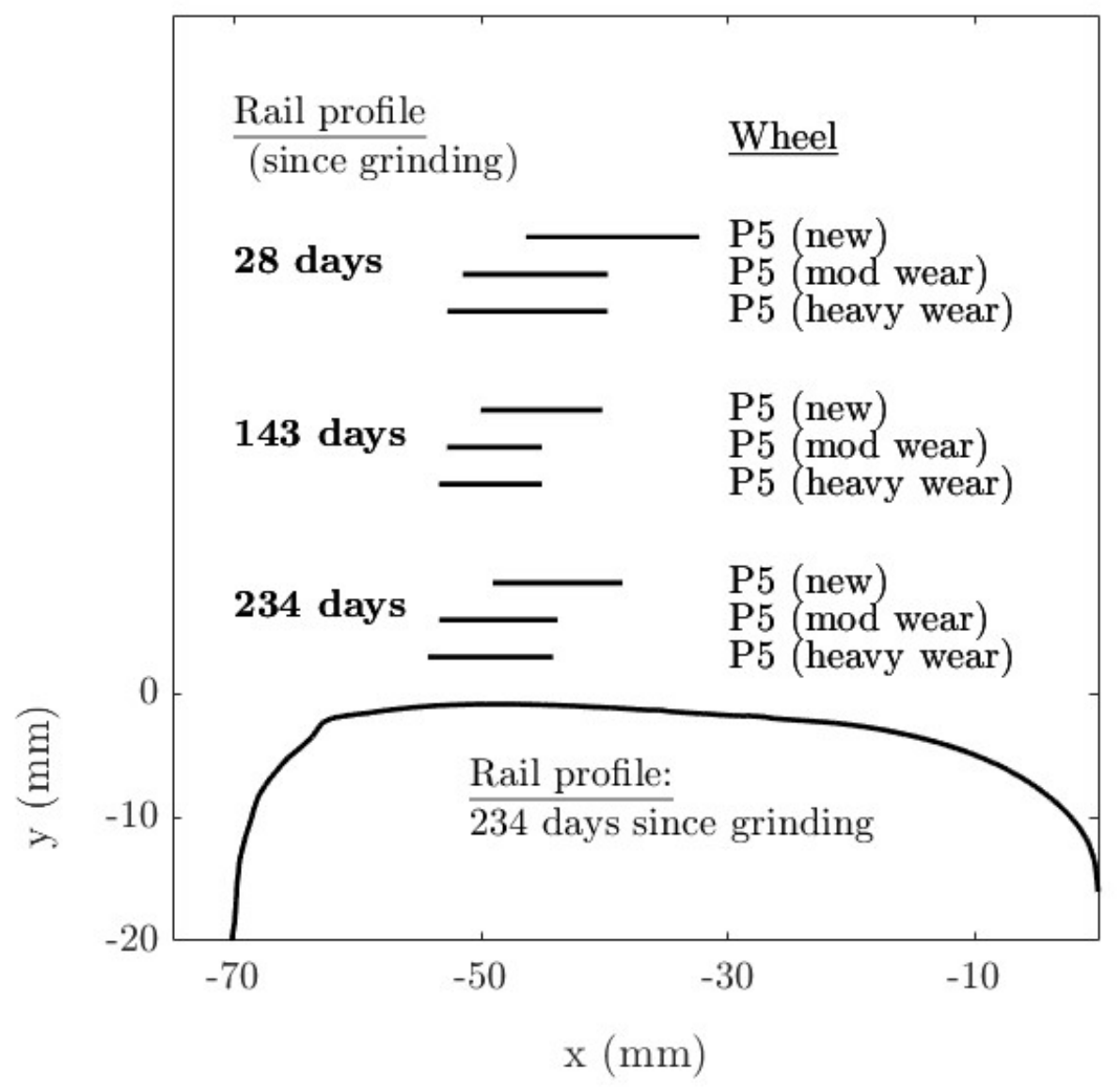

Figure 4 Running bands Site A (low rail) [rail shape 234 days after grinding] 


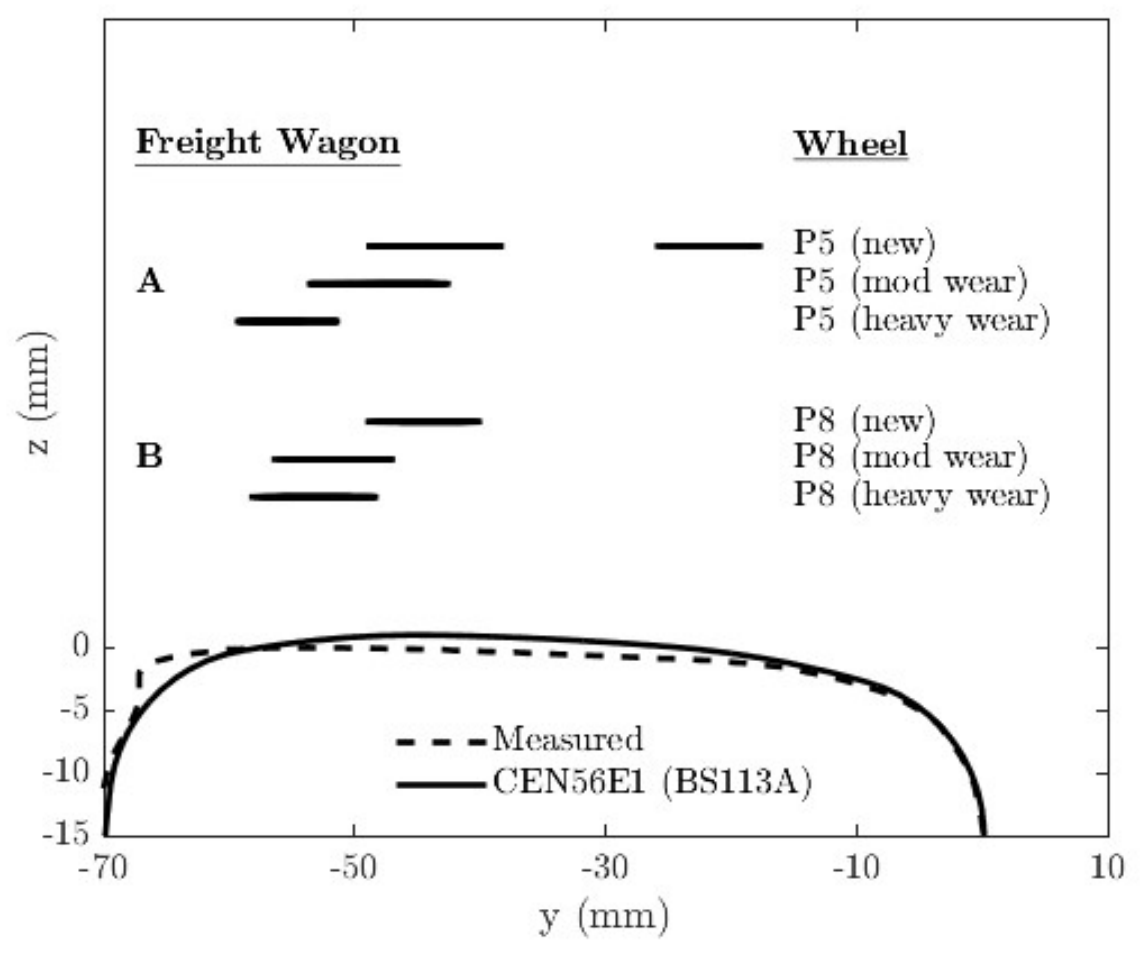

Figure 5 Running bands Site B (low rail)

\subsection{Contact shape}

To assess the validity of using shakedown maps with a fixed circular contact area, the longitudinal and lateral semi-axis, $a$ and $b$, for each contact are plotted in Figure 6. Bounds showing a circular contact $b / a=1$ and the most extreme case considered by Ponter et. al. [5] (i.e. $b / a=0.25$ ) are also plotted. Therefore, it can be seen that the shakedown maps in Ponter et. al. cover the range of contact shapes found.

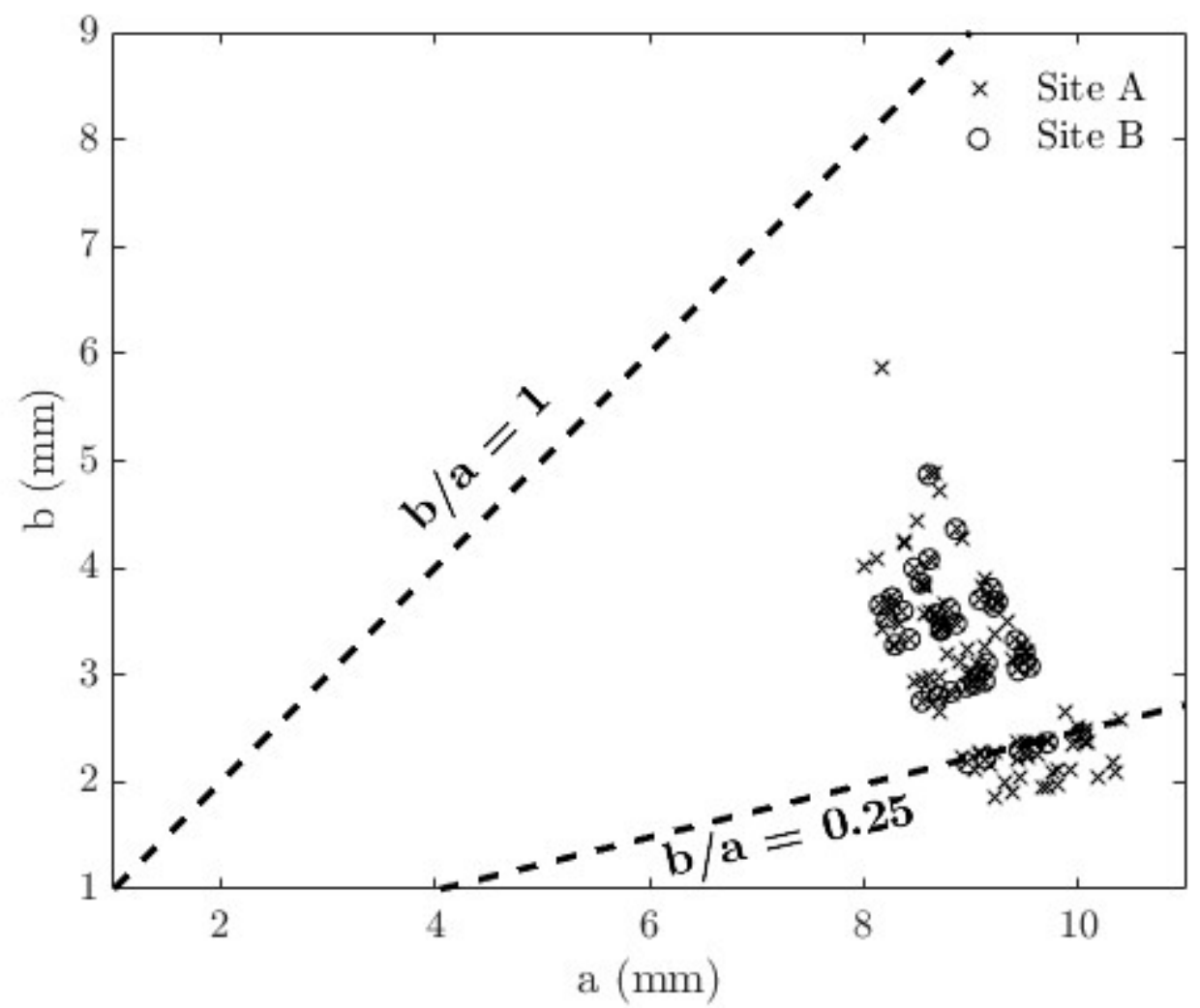

Figure 6 Summary of contact shape on low rail 


\subsection{Tangential tractions}

The orientation of the tangential contact forces on the low rail are plotted in Figure 7; note the figure include results for both first and second wheelsets for the full range of speeds simulated These show a range of traction orientations are present at both sites. These varying tangential traction orientations could reduce the shakedown limit [8]. Further, Ponter et al. [5] only investigated different tangential force orientation for circular contacts. Therefore, Figure 6 and Figure 7 imply that full-range of operating conditions are not covered in the published shakedown maps.

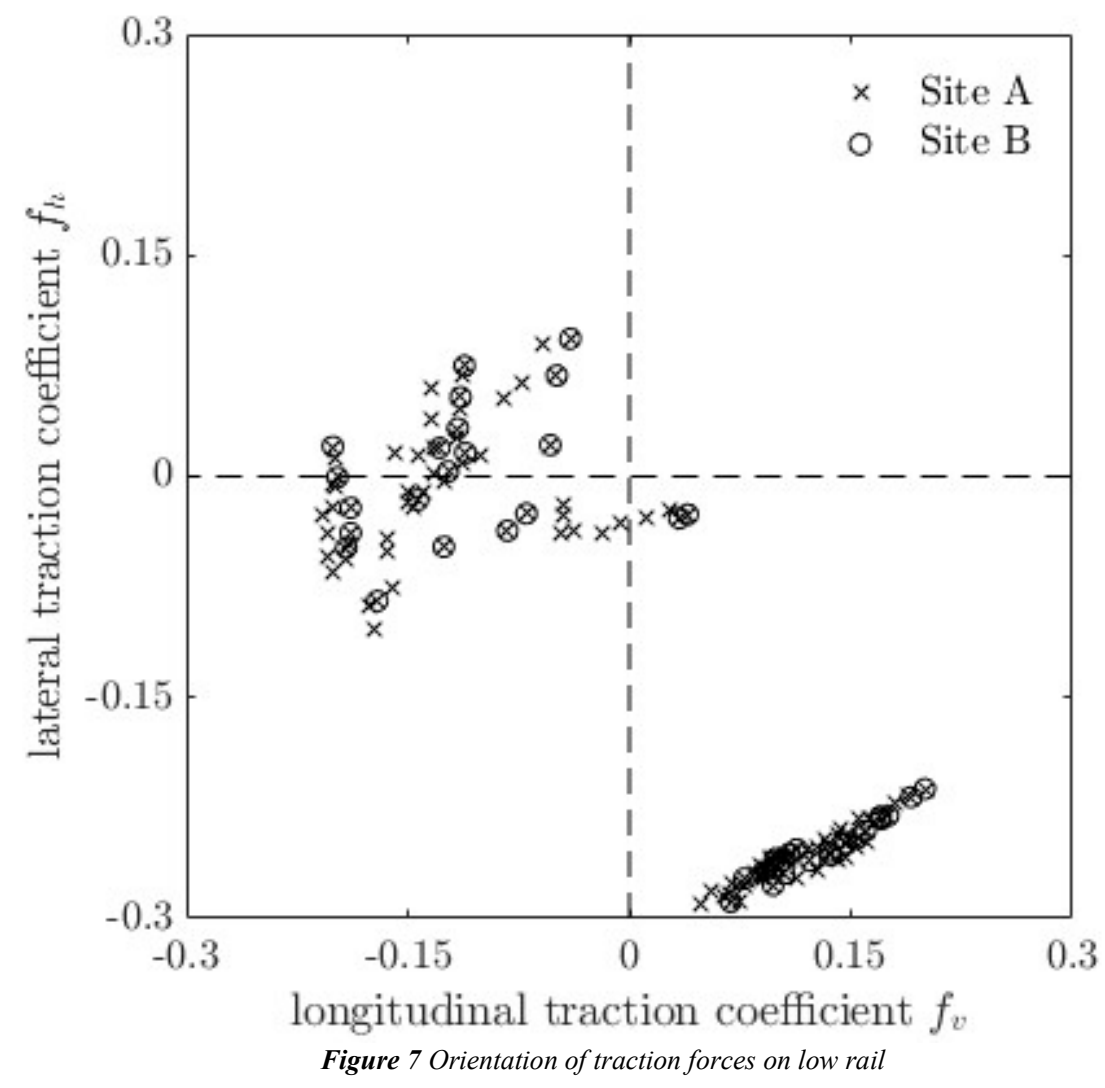

\section{Finite element analysis 4.1. Model description}

The shakedown maps in Figure 2 were derived assuming an elastic perfectly-plastic material model; which is a simplification compared to the real behaviour of rail steels. Further, these do not provide information on the rate of lateral plastic flow accumulation. To study the influence of a more realistic material model and investigate the rate of lateral plastic flow accumulation, a static non-linear finite element model was developed within ANSYS Mechanical [21]. The Chaboche non-linear kinematic material model [22] was selected due to its ready availability within ANSYS and suitable published material parameters for R260 rail steel. Chaboche kinematic hardening translates the original von Mises yield criterion without increasing the size of the yield surface. In this case, Chaboche parameters optimized for low cycle plastic deformation, see Appendix A, and tensile yield stress $\sigma_{\mathrm{y}}=443 \mathrm{MPa}$ have been used throughout. These parameters limit the ultimate strength to $1150 \mathrm{MPa}$ (i.e. hardening levels off).

Several potentially significant simplifications, consistent with the derivation of the shakedown maps, have been made. By adopting similar simplifications, results can be readily compared versus the shakedown maps to assess the influence of the more realistic material model. Hertzian contact conditions with full slippage were assumed throughout. Therefore, the contact on the rail is modelled as a moving pressure distribution, saving considerable computational expense. The rail was modelled as a rectangular region. All boundaries apart from the running surface were fixed. Fixed boundaries were at a sufficient distance from the applied contacts so as to not unduly influence results, thus approximating the half-space assumption in the shakedown maps. To study the influence of different contact conditions four scenarios were considered: (a) $b / a=1$, lateral traction; (b) $b / a=1$, longitudinal traction; (c) $b / a=0.25$, lateral traction; and (d) $b / a=0.25$, longitudinal traction. A range of normal loads and traction coefficients were simulated to cover the full range in section 3 . Depending on the case considered, between 41,040 and 57,000 linear hexahedral elements were used to discretise the problem domain including a finer mesh in the region closest to the contact application. To simulate the passage of a wheel, the contact patch was incrementally moved a distance of 2.5a. Between 125-200 individual increments were used to simulate a single passage of a wheel. The sensitivity of results to both length of contact movement and the number of increments was 
tested. Neither parameter was found to significantly influence results. For each contact condition, four wheel passages were simulated.

\subsection{Results}

The most obvious evidence of plastic flow is the characteristic deformed shape as shown in Figures 4 and 5. Therefore, a measure of lateral plastic flow is necessary that reflects this. To this end, a bespoke measure of plastic flow has been derived.

$$
s f_{i}=\frac{\int\left|z_{i}-z_{0}\right| \boldsymbol{d} \boldsymbol{s}}{a b \pi}
$$

where $z_{0}$ is the vertical coordinate of the original rail profile and $z_{i}$ the vertical coordinate of the deformed rail surface after the $i$ th wheel passage in the FEA simulations. The integral term in the numerator measures the change in the surface profile. This integral can be visualized as the area between the original profile and the deformed profile, as illustrated in Figure 8. The denominator term is the area of the contact and normalizes the result to produce a dimensionless output for easy comparison between applied contacts. In the following discussion, $s f_{i}$ was evaluated at a cross-section mid-way along the path traversed by the contact. $s f_{i}$ only explicitly captures vertical deformation. At the mid-way cross-section used to evaluate $s f_{i}$, overall vertical deformation should be closely linked with lateral deformation as the material model requires incompressible plastic deformations. The deformed shape in Figure 8 is typical of those found in the finite element results. In reality, this deformed shape could not occur as the contact patch would 'spread' to the surrounding rail surface thus resulting in an increased contact area. Additionally, the contact position could change between wheel passes thus potentially reversing plastic deformation from previous wheel passes. However, $s f_{i}$ is directionless and thus should provide a measure of likely surface deformation without implying a particular deformation mechanism.

To access the ongoing incremental surface deformation, the difference in $s f_{i}$ for the final two wheel passages, $s f_{4}-s f_{3}$, has been used. For easy, $s f_{4}-s f_{3}$ is referred to as $\Delta s f$ for the remainder of the paper. For this to be an accurate measure of longer term behaviour it is necessary that rail has 'shaken down' or is approaching a constant rate of ratchetting. While this is true for the majority of the finite element models, a smaller number particularly further from the relevant shakedown limit had not settled to a constant ratchetting rate after four cycles.

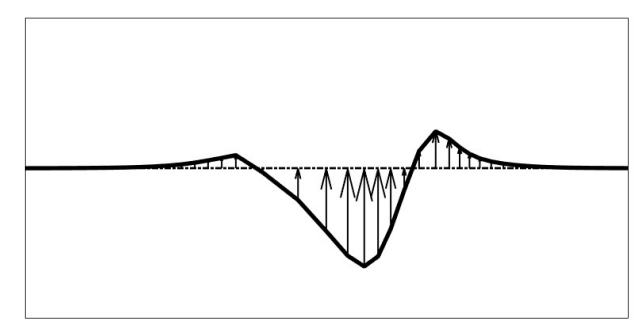

Figure 8 Surface deformation integral

To allow comparison with existing shakedown maps, $\Delta s f$ is plotted in Figure 9 as a contour map with the same axes as those commonly employed for shakedown maps. In these plots, a shear strength $k=\frac{\sigma_{y}}{\sqrt{3}}$, consistent with the von Mises yield criterion, was used to normalize the peak normal stress $p_{0}$. If available, the shakedown map corresponding to the case has been overlain.

For all four cases considered, the FE models failed to converge at higher peak stresses and/or traction ratios; in most cases below the adjusted shakedown maps. These regions, where the FE model failed to converge, are plotted in the contour plots as white space. Lack of convergence was associated in all cases with gross plastic deformations. The number of wheel passages before lack of convergence occurred varied roughly in proportion to the distance from the shaded area of the relevant contour plot. Some further measures, such as adaptive re-meshing, may have achieved convergence for a proportion of the failed models. However, a ratchetting failure would clearly still have occurred; so additional efforts to achieve model convergence were discontinued. 


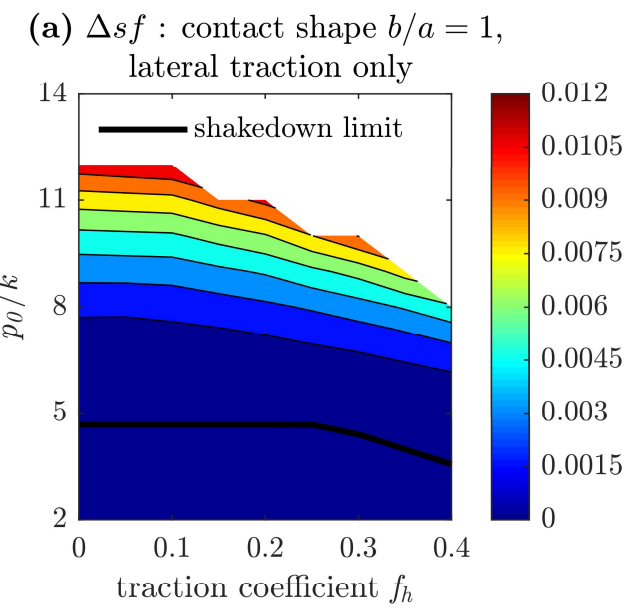

(b) $\Delta s f:$ contact shape $b / a=1$,

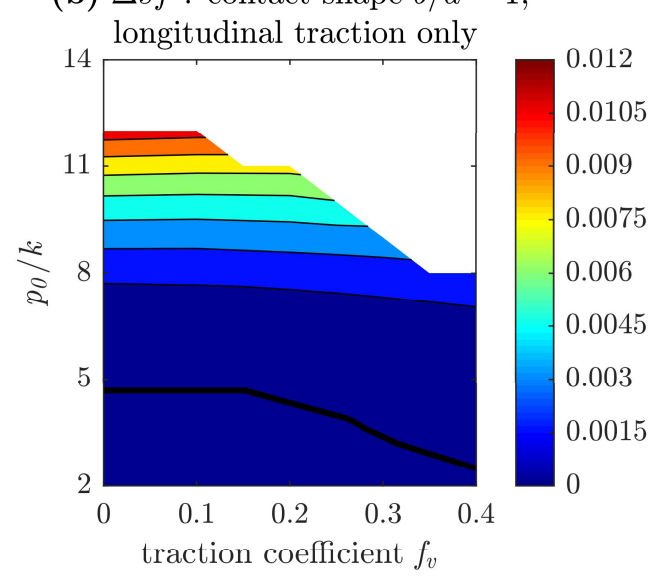

(c) $\Delta s f:$ contact shape $b / a=0.25$, lateral traction only

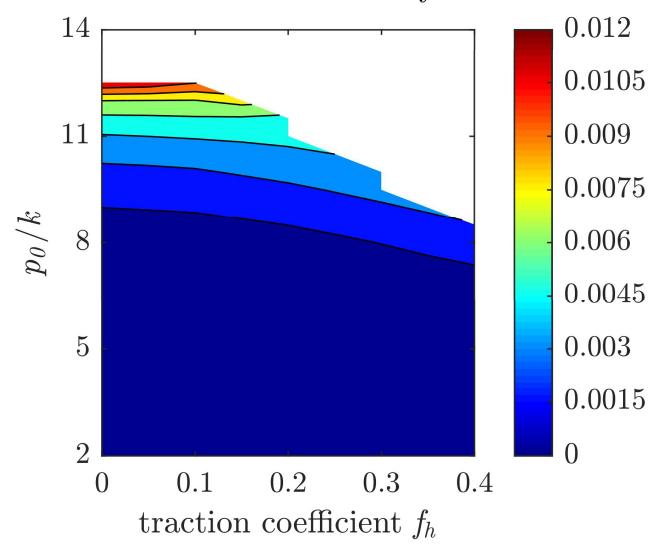

(d) $\Delta s f$ : contact shape $b / a=0.25$, longitudinal traction only

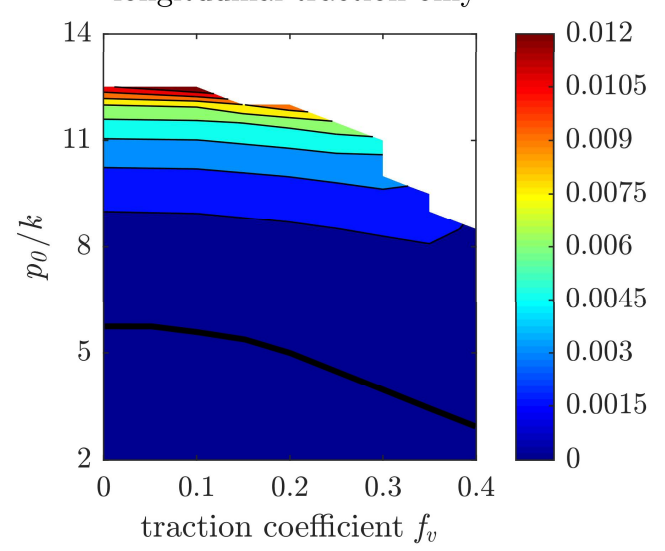

Figure $9 \boldsymbol{\Delta} \boldsymbol{s}$ for different scenarios

As might be expected, scenarios (a) and (c), described in section 4.1, with only lateral traction resulted in greater $\Delta s f$ values as compared to scenarios (b) and (d) respectively with equivalent contact shapes but longitudinal traction only. As suggested by the shakedown maps in Figure 2, the elliptical contact shapes resulted in smaller $\Delta s f$ values compared to equivalent circular contacts. Figure 9 suggests that distance to the shakedown limit line (where available) is a reasonable measure of likely plastic flow; where tractions are purely lateral. When traction forces are purely longitudinal, little discernible increase in $\Delta s f$ is observed with increasing traction coefficient $f_{v}$. However, increased longitudinal deformation not captured by $s f_{i}$ does occur. In longitudinal traction, $\frac{p_{0}}{k}-\left(\frac{p_{0}}{k}\right)_{i n t}$ would therefore appear a more promising predictor of plastic flow; where $\left(\frac{p_{0}}{k}\right)_{i n t}$ is the intercept of the shakedown map with the $\frac{p_{0}}{k}$ axis. However, the use of shakedown maps is complicated by the absence of published maps for scenario (c). Distance from the shakedown limit line has been used to predict not only plastic deformation but also rolling contact fatigue and wear [e.g. 16]. Therefore, shakedown maps would appear a valuable assessment tool when properly understood.

\section{Site analysis}

In order to apply the results in section 4 to sites $\mathrm{A}$ and $\mathrm{B}$, a simple linear interpolation scheme has been used to assess the relative plastic flow associated with the contacts in section 3 . The linear interpolation scheme is as follows:

i. $\quad$ find the resultant traction coefficient and peak stress $p_{0}$ for each contact, normalizing $p_{0}$ by $k$;

ii. use linear interpolation to find $\Delta s f$ for each scenario (a)-(d) in section 4, using the resultant traction coefficient (not the longitudinal and lateral traction coefficients) and normalized $p_{0}$ from step i;

iii. linearly interpolate, based on the traction orientation (i.e. ratio of lateral to longitudinal traction force) and contact shape, between the four values obtained in step ii to find a single value for $\Delta s f$;

iv. multiply the interpolated $\Delta s f$ value by contact area $\pi a b$ to find a value in $\mathrm{mm}^{2}$, rather than the dimensionless value in step iii.

The interpolation scheme described above assumes the contribution of spin moment to be minimal. However, it should be noted that contacts included varying amounts of spin moment. Additionally, a number of contacts for Site A fell outside the shaded region in Figure 9. In these cases, it was not possible to obtain a $\Delta s f$ using the interpolation scheme above. $\pi a b \cdot(\Delta s f)$ values for different wheel profile/vehicle combinations have been calculated for individual wheelsets and summed to produce a total per vehicle. These results reveal that running at cant excess significantly increases $\pi a b \cdot(\Delta s f)$ 
on low rails regardless of wheel profile/vehicle combination, see Figure 10.

The increased $\pi a b \cdot(\Delta s f)$ can be traced back to increased normal forces on the low rail to allow balancing at cant excess. The reverse is likely to be true in the case of high rail tread contacts, where reducing $\pi a b \cdot(\Delta s f)$ is expect with cant excess. The situation in high rail flange contacts is more complex. Such flange contacts occur at cant excess. However, the significant spin moments associated with these contacts suggest the interpolation scheme above to be inappropriate.

For Site B and wagon A, $\pi a b \cdot(\Delta s f)$ increases significantly with wheel wear, particularly from moderately worn to heavily worn P5 profiles. This could be due to the much broader range of running positions for P5 wheel profiles relative to P8 wheel profiles, see Figure 5. At new to moderate levels of wear, the laden freight wagon A (with P5 wheel profile) produces smaller low rail $\pi a b \cdot(\Delta s f)$ compared to the laden freight wagon B/P8 combination.

Finally, an aggregated value of $\pi a b \cdot(\Delta s f)$ per year $\left(\mathrm{mm}^{2} / \mathrm{yr}\right)$ was calculated for both sites. However, these aggregated values were unrealistically high. For Site A, a simple summation of the plastic flow indicator considerably overestimated measured plastic flow indicator, calculated using measured profiles. A couple factors may contribute to this: (1) $\Delta s f$ is not an accurate longer term measure, see section 4.2 ; (2) deformation from individual contacts reversed by subsequent wheel passes; (3) no residual stress or strain due to prior wheel passes has been assumed in FEA; (4) some plastically deformed material maybe remove through wear.
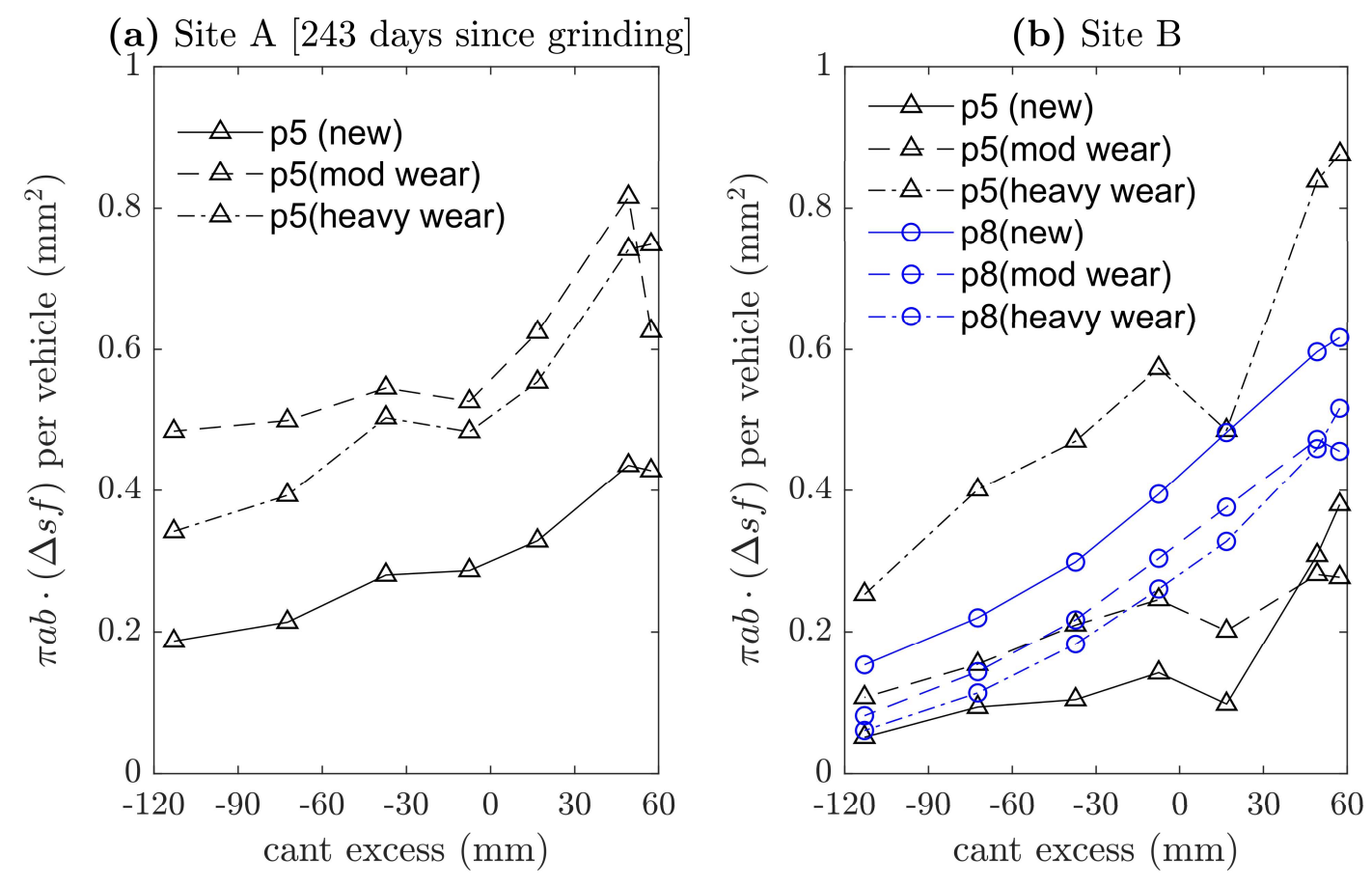

Figure 10 Influence of cant excess/deficiency on $\boldsymbol{\pi} \boldsymbol{a b} \cdot(\boldsymbol{\Delta} \boldsymbol{s} \boldsymbol{f})$ for low rails

\section{Conclusions}

The applicability of shakedown maps to wheel-rail contacts has been examined. In particular, the divergence of such contacts from the commonly used shakedown map by Ponter et al [4] has been highlighted. Ponter et al [4] assumed circular contacts with traction in the direction of travel. On the other hand, vehicle dynamic simulations for two trial sites have demonstrated that contacts on the low rail of tight radius curves are typically elliptical in shape and characterised by tangential contact forces at an angle to the direction of travel. Use of alternative shakedown maps, such as those published by Ponter et al [5], is therefore recommended. However, these do not cover the full range of contact conditions identified for the trial sites. In particular, no shakedown map is available for elliptical contacts with lateral contact forces.

The shakedown maps in Ponter et al [4], [5] both assume Hertzian contact conditions including a half-space assumption. Vehicle dynamic simulation suggest this to be a valid assumption for the majority of contacts at the trial sites investigated in this work. However, a small number of contacts may be approaching the field side of the low rail and edge effects could be significant for these contacts.

Rail steels exhibit complex post yield behaviour including non-linear hardening. However, shakedown theory used to derive the shakedown maps assumes an elastic perfectly plastic material model with no post yield hardening. Finite element analysis in this work using a more realistic Chaboche model has shown that distance above the shakedown limit is still a good indicator of likely plastic flow. However, the best measure to calculate this distance will depend on the orientation of the resultant traction force.

A simple scalar indicator has been developed to quantify plastic flow within the finite element models. The proposed indicator can be viewed as the area between the original rail profile and the deformed profile. The indicator thus includes deformation in the vertical and lateral directions but excludes longitudinal deformation along the rail. The proposed measure corresponds well with plastic flow identified in measured rail profiles for the trial sites. Therefore, a similar calculation using field data is possible where profiles measured at different dates are available. 
A simple linear interpolation scheme, using the finite element results, was developed to allow the plastic flow indicator to be calculated for most contact conditions. The interpolation scheme has been applied to the two trial site. These show that more severe low rail plastic flow might be expected when running at cant excess. A simple summation of the plastic flow indicator for a single trial site considerably overestimated measured plastic flow indicator, calculated from measured profiles. This discrepancy maybe due to deficiencies in the finite element modelling and/or contacts reversing prior plastic deformation.

Real contact conditions differ from those assumed in shakedown maps in a number of ways not covered explicitly by the current study. These include partial slip conditions and contacts approaching the edge of the rail. A similar methodology to that used in the current study is envisaged to investigate these two factors. Additionally, the assumptions behind Hertzian contact theory may be violated in which case more complex finite element models employing contact algorithms may be needed.

\section{Acknowledgments}

The authors would like to thank RSSB for funding this work through their Strategic Partnership with the University of Huddersfield Institute of Railway Research, as well as Network Rail and British Steel who have supported this work by providing measured field data and guidance through a project steering committee.

\section{Appendix A}

Chaboche parameters optimized for low cycle plastic deformation by [23] were used for the FEA. A single set of kinematic hardening parameters, $\mathrm{C}_{1}=40995 \mathrm{MPa}$ and $\gamma_{1}=58.0$, were used as per [23].

\section{References}

[1] E. Magel, M. Roney, J. Kalousek, and P. Sroba, "The blending of theory and practice in modern rail grinding," Fatigue Fract. Eng. Mater. Struct., vol. 26, no. March, pp. 921-929, 2003.

[2] W. Koiter, "A new general theorem on shakedown of elastic-plasitc structures," Konink Ned Akad Wet B, vol. 59, pp. 24-34, 1956.

[3] E. Melan, "Der spannungsgudstand eines Henky-Mises schen Kontinuums bei Verlandicher Belastung," Sitzungberichte der Ak Wissenschaften Wie, vol. Ser. 2A, 1938.

[4] A. Ponter, A. D. Hearle, and K. L. Johnson, "Application of the kinematical shakedown theorem to rolling and sliding point contacts,” J. Mech. Phys. Solids, vol. 33, no. 4, pp. 339-362, 1985.

[5] A. R. S. Ponter, H. F. Chen, M. Ciavarella, and G. Specchia, "Shakedown analyses for rolling and sliding contact problems,” Int. J. Solids Struct., vol. 43, no. 14-15, pp. 4201-4219, Jul. 2006.

[6] A. F. Bower, K. L. Johnson, and J. Kalousek, "A ratchetting limit for plastic deformation of a quarter-space under rolling contact loads," in Contact mechanics and wear of rail/wheel systems: 2nd symposium, 1987, pp. 117-132.

[7] K. L. Johnson, "A Graphical Approach to Shakedown in Rolling Contact,” in Applied Stress Analysis, Dordrecht: Springer Netherlands, 1990, pp. 263-274.

[8] S. Foletti and H. J. Desimone, “Application of shakedown maps under variable loads," Eng. Fract. Mech., vol. 74, no. 4, pp. 527-538, Mar. 2007.

[9] Z. Wei, Z. Li, Z. Qian, R. Chen, and R. Dollevoet, "3D FE modelling and validation of frictional contact with partial slip in compression-shift-rolling evolution,” Int. J. Rail Transp., vol. 4, no. 1, pp. 20-36, Jan. 2016.

[10] C. L. Pun, Q. Kan, P. J. Mutton, G. Kang, and W. Yan, "An efficient computational approach to evaluate the ratcheting performance of rail steels under cyclic rolling contact in service," Int. J. Mech. Sci., vol. 101-102, pp. 214-226, 2015.

[11] Z. Wen, L. Wu, W. Li, X. Jin, and M. Zhu, "Three-dimensional elastic-plastic stress analysis of wheel-rail rolling contact," Wear, vol. 271, no. 1-2, pp. 426-436, 2011.

[12] A. R. S. Ponter, "A general shakedown theorem for elastic plastic bodies with work hardening," in Proc. SMIRT-3, 1975, p. paper L5/2.

[13] D. C. Pham and D. Weichert, "Shakedown analysis for elastic-plastic bodies with limited kinematic hardening," Proc. R. Soc. A Math. Phys. Eng. Sci., vol. 457, no. 2009, pp. 1097-1110, May 2001.

[14] K. L. Johnson, "Plastic flow, residual stress and shakedown in rolling contact," in Proc. Int. Symp. on Contact Mechanics and Wear of Rail/Wheel Systems II, 1987, pp. 83-97.

[15] A. F. Bower and K. L. Johnson, "Plastic flow and shakedown of the rail surface in repeated wheel-rail contact," Wear, vol. 144, no. 1-2, pp. 1-18, 1991.

[16] A. F. Bower and K. L. Johnson, "Shakedown, Residual Stress and Plastic Flow in Repeated Wheel-Rail Contact," in Rail quality and maintenance for modern railway operation, J. J. Kalker, Ed. Kluwer Academic Publishers, 1993, pp. 239-249.

[17] Greenwood Engineering, "https://www.greenwood.dk/miniprof.php." .

[18] Resonate Group Ltd, "http://www.vampire-dynamics.com/," 2018. . 
[19] Railway Group Standard, Standard GMRT2466, Railway Wheelsets, Issue 4, RSSB. .

[20] J. J. Kalker, "Wheel-rail rolling contact theory," Wear, vol. 144, no. 1-2, pp. 243-261, 1991.

[21] ANSYS Inc, "https://www.ansys.com/en-gb/products/structures," 2018. .

[22] J.-L. Chaboche and J. Lemaitre, Mechanics of solid materials, . Cambridge Univ. Press, 1990.

[23] INNOTRACK, "Simulation of material deformation and RCF," 2009. 